\title{
A aprendizagem social subjacente às práticas de negociação: uma abordagem das questões socioambientais em uma organização multiatores
}

\author{
Ana Sílvia Rocha Ipiranga \\ Universidade Estadual do Ceará (Uece) \\ Michelle Firmino Celestino Moreira \\ Universidade Estadual do Ceará (Uece) \\ Luma Louise Sousa Lopes \\ Universidade Estadual do Ceará (Uece) \\ Luís André Aragão Frota \\ Universidade Estadual do Ceará (Uece) \\ Luciana Madeira Barros Coimbra \\ Universidade Estadual do Ceará (Uece)
}

\begin{abstract}
Este estudo teve por objetivo descrever as práticas de aprendizagem subjacentes ao processo de negociação em uma organização multiatores de caráter socioambiental. A pesquisa utilizou a estratégia do estudo de caso qualitativo e a coleta de dados teve por base a triangulação de técnicas, visando ao enriquecimento da interpretação. Para a análise, optou-se pela aplicação dos procedimentos das práticas discursivas. Constatou-se que a participação se revela importante prática de aprendizagem da negociação e da negociação da aprendizagem subjacente, por meio da qual os saberes relacionados aos papéis e estilos colocados em ação pelos multiatores estão vinculados aos fazeres construídos coletivamente, definindo, nessas fronteiras e interstícios, as deliberações normativas sobre as questões socioambientais.
\end{abstract}

Palavras-chave: aprendizagem social; negociação socioambiental; multiatores.

Aprendizaje social subyacente a las prácticas de negociación: abordaje de las cuestiones socioambientales en una organización con múltiples actores

Este estudio tuvo como objetivo describir las prácticas de aprendizaje subyacentes al proceso de negociación en una organización con múltiples actores de naturaleza socio-ambiental. La investigación utilizó la estrategia del estudio de caso cualitativo y la recogida de datos se basó en la triangulación

Artigo recebido em 30 set. 2012 e aceito em 11 nov. 2013. 
de técnicas, con el fin de enriquecer la interpretación. Para el análisis, se optó por aplicar los procedimientos de las prácticas discursivas. Se constató que la participación se revela una práctica importante de aprendizaje de la negociación y negociación de la aprendizaje subyacente, a través de la cual los conocimientos relacionados con los papeles y estilos puestos en acción por los múltiples actores están obligados a los hechos construidos colectivamente, definiendo, en eses límites e intersticios, las deliberaciones normativas acerca de las cuestiones socio-ambientales.

Palabras clave: aprendizaje social; negociación socio-ambiental; múltiples actores.

Social learning underlying the negotiation practices: approach to socio-environmental issues in an organization with multiple actors

This study aimed to describe the learning practices underlying the negotiation process in an organization with multiple actors and a socio-environmental nature. The research used the qualitative case study strategy and data collection was based on the triangulation techniques, aiming to enrich interpretation. For the analysis, we chose to apply the procedures of discursive practices. We found out that participation shows to be an important practice of the negotiation learning and the underlying learning negotiation, through which some knowledge related to roles and styles put into action by the multiple actors are bound to some collectively constructed doing, defining, at these boundaries and interstices, the normative deliberations on socio-environmental issues.

KEYWORDs: social learning; socio-environmental negotiation; multiple actors.

\section{Introdução}

As mudanças que afetam o ambiente socioambiental como consequências da ação humana ocorrem em uma intensidade tal que a natureza não consegue suportar, em uma velocidade que não permite a ela se recuperar nem compensar as perdas. Estudiosos alertam que, caso seja mantido o atual ritmo de devastação ambiental, em breve o planeta não será capaz de fornecer os recursos naturais em quantidade suficiente à demanda populacional.

A literatura pertinente apresenta diferentes abordagens para tratar as questões socioambientais, que deslocam seus focos entre os modelos tradicionais de gestão dos recursos naturais e entre as abordagens integradoras que envolvem processos multiatores. Os modelos tradicionais se moldam predominantemente em termos de suas características técnico-econômicas com pouca presença da opinião pública, enquanto as abordagens integradoras relacionadas às agendas que têm como base os processos multiatores envolvem as esferas públicas e privadas com atuação, sobretudo, em espaços coletivos e, portanto, abertas ao escrutínio público (Hemmati, 2002; Mostert, 2003; Warner, 2005).

Para Jacobi, Granja e Franco (2006), essa abordagem integradora das relações entre as esferas pública e privada, subjetivas e intersubjetivas amplia a possibilidade de constituição de identidades coletivas em espaços propícios à convivência, debates e tomada de decisão, sendo estes caracterizados pelos assim chamados fóruns e/ou mesas de negociação. Tendo como base a diversidade de percepções, as questões socioambientais em discussão trazem para a 
mesa de negociação uma multiplicidade de aspectos antes ignorados, sendo este o caminho para obter resultados integrados e sustentáveis. Os atores, ao perceberem a importância do significado da participação e do envolvimento das múltiplas vozes, elegem este caminho para lidar com a crescente diversidade e complexidade das deliberações de cunho socioambiental (Jacobi, Granja e Franco, 2006; Warner, 2005).

Os fóruns de negociação compostos para a discussão das questões socioambientais têm crescido em importância no Brasil, representando um movimento em prol da sustentabilidade, mobilizando os diferentes segmentos sociais com o objetivo de solucionar os problemas. Nesse contexto, alguns autores, ao discutirem as diferentes abordagens envolvidas nos processos multiatores de negociação, têm articulado, segundo a perspectiva da psicologia e da educação, a dimensão da aprendizagem social como ferramenta que contribui na construção de consensos e da tomada de decisão (Pahl-Wostl, 2002; HarmoniCOP, 2003; Tippet et al., 2005; Warner, 2005; Jacobi, Granja e Franco, 2006).

Mais recentemente, observou-se que um conjunto de estudos tem ampliado a discussão da aprendizagem social como uma abordagem para a resolução de problemas complexos no contexto dos processos multiatores (Jacobi e Barbi, 2007). O mérito desses estudos é ter examinado a construção de capacidades entre grupos de stakeholders no compartilhamento de conhecimentos para a ação, impactando na resolução de problemas relacionados às questões de recursos naturais (Kilvington, 2007, 2010; Leys e Vanclay, 2010). Alguns desses estudos discutiram as conexões conceituais entre aprendizagem social no contexto das organizações multiatores, iluminando nessa discussão a ideia de aprendizagem para a sustentabilidade (Bouwen e Taillieu, 2004; Glasser, 2007; Swartling et al., 2011), inclusive no Brasil, como as recentes pesquisas de Oliveira e Sinisgalli (2010), Souza e Beduschi Filho (2010) e D’Angelo e Brunstein (2013).

Apesar desse corpo crescente de trabalhos teóricos e empíricos, releva-se que estes temas ainda não foram suficientemente explorados na literatura brasileira pertinente aos estudos organizacionais, sobretudo, ao enfatizarem que a aprendizagem emerja de um contexto de interações (knowing), através de diferentes formas de participação e em um fórum multiatores de negociação, sendo este conhecimento continuadamente refletido, construído, reconstruído e reproduzido (Elkjaer, 2001; Elkjaer e Wahlgren, 2005; Nicolini, Gherardi e Yanow, 2003; Schatzki, 2006).

Nesse sentido e considerando estas discussões, pressupõe-se que a participação no contexto de uma organização multiatores se releva como importante prática de aprendizagem da negociação e da negociação da aprendizagem que lhe é subjacente. Com base nesse pressuposto, este estudo tem como objetivo descrever as práticas de aprendizagem social subjacentes ao processo de negociação em uma organização multiatores de caráter socioambiental.

A escolha do campo empírico do estudo recaiu sobre o Conselho Estadual de Meio Ambiente (Coema) do estado do Ceará, que se caracteriza como uma organização multiatores na medida em que se compõe por um fórum de negociação envolvendo participantes de diferentes instituições e dos mais diversos segmentos sociais, que têm como objetivo buscar soluções 
para as questões de natureza socioambiental por meio do contraponto de ideias e perspectivas sobre uma mesma pauta, a fim de aprovar (ou não) projetos que vão impactar de forma direta ou indireta os cenários sociais e ambientais do estado.

O artigo está estruturado em seis seções, além das notas introdutórias. As seções 2 e 3 e suas respectivas subseções articulam as discussões sobre a abordagem da aprendizagem social e dos processos de negociação no contexto das organizações multiatores. A seção 4 aborda os procedimentos metodológicos da pesquisa e, finalmente, as seções 5 e 6 apresentam as análises e discussões do estudo seguidas das considerações finais.

\section{As organizações multiatores e a abordagem das questões socioambientais}

A abordagem das questões socioambientais consiste na gestão dos recursos naturais e de operações em diferentes situações — nas organizações e na esfera pública — visando a preservação do meio ambiente e/ou a recuperação de áreas degradadas por suas atividades (Ferreira, 2003). Também é entendida como uma forma possível de evitar os conflitos e controvérsias socioambientais, por meio de processos de negociação, destacando, assim, o papel dos múltiplos atores envolvidos e impactados pelos empreendimentos (Hemmati, 2002).

Destaca-se como uma das causas dos problemas socioambientais o modelo tradicional de gestão dos recursos naturais. Mostert (2003) afirma que estes modelos de gestão foram moldados predominantemente em termos de suas estruturas e características técnico-econômicas, minimizando a importância das dimensões socioambientais.

Segundo Warner (2005), para redirecionar os rumos da gestão socioambiental se faz necessário o desenvolvimento de modelos integrados de gestão desses recursos. Um caminho para isso seria a adoção de processos de negociação multiatores, envolvendo as esferas públicas e privadas, bem como atores da sociedade civil, além do próprio Estado. Essa gestão integrada ocorre em ambientes propícios destinados à discussão e tomada de decisão acerca das questões socioambientais; estes são caracterizados pelos assim chamados fóruns e/ou mesas de negociação (Jacobi, Granja e Franco, 2006; Warner, 2005).

Um conceito amplamente aceito dos processos multiatores foi apresentado por Steins e Edwards (1998), que o definem como um órgão de decisão (voluntário ou estatutário) envolvendo diferentes atores que percebem o problema de gestão como recurso e a necessidade da interdependência entre os múltiplos atores que se reúnem para chegar a um acordo sobre as ações que serão implementadas para resolvê-lo.

Roling e Woodhill (2001) também fizeram uso da metáfora da mesa-redonda ao redor da qual múltiplos atores com suas diferentes perspectivas interagem, construindo em um espaço de conflito multi-interessados diálogos, visando a partir da negociação e da aprendizagem social a resolução por meio da tomada de decisão e da ação concertada.

Para Jacobi, Granja e Franco (2006), essa abordagem integradora das relações entre as esferas subjetivas e intersubjetivas, pública e privada amplia a possibilidade de constituição de identidades coletivas em espaços de convivência e debates. Para os autores, nesses espaços 
os conflitos adquirem status de desafios a serem explicitados e negociados a partir de diálogos horizontalizados e de aprendizagem do exercício da participação, mediando e refletindo experiências de diferentes sujeitos e múltiplos atores sociais na construção de projetos de intervenção coletivos.

Visando promover processos de deliberações justos e efetivos na resolução dos problemas, Dore e Lebel (2010) sugerem quatro características desejáveis de uma organização multiatores: o contexto, os processos, o conteúdo e os resultados.

Contudo, salienta-se que as organizações multiatores devem ser consideradas um complemento às formas de governanças existentes e não como suas substitutas. Além disso, elas não podem ser encaradas como remédio para todos os males (Warner, 2006). As dificuldades enfrentadas por elas são inúmeras, os obstáculos estão relacionados principalmente ao seu processo, dada a complexidade da dinâmica da negociação. Porém, a participação dos atores no contexto dessas organizações é essencial, pois é mediante a interação continuada entre os diferentes e múltiplos atores participantes que a mudança social acontece.

Considera-se, ainda, que a abordagem das questões socioambientais nas organizações multiatores, ao se basear nas dimensões da diversidade, democracia e da aprendizagem social, se caracteriza pelo fato de reunir em um fórum de negociação diferentes grupos que nunca interagiram entre si. Nessa linha de discussão, salientam-se as contribuições de diversos autores sobre as implicações práticas do papel potencial da aprendizagem social na gestão dos recursos naturais ao propiciar oportunidades de aprendizagens aos múltiplos atores que se engajam e participam desses fóruns de negociação (Warner, 2005; Muro e Jeffrey, 2008; Leys e Vanclay, 2010).

Tendo como base o objetivo do presente estudo, articularemos a seguir os conceitos de negociação e a criação de um contexto favorável para a tomada de decisão, e na próxima sessão será abordada a perspectiva da aprendizagem social subjacente às práticas de negociação no contexto das organizações multiatores relacionadas às questões socioambientais.

\subsection{Os processos de negociação e a criação de um contexto favorável para a tomada de decisão}

As definições para o conceito de negociação se diferem e se complementam entre si. Alguns autores, ao focalizarem o negociador na interação face a face, enfatizam a intenção de se obter algo em troca, abordando a questão da comunicação e dos processos de resolução de conflitos e obtenção de consensos (Fisher e Ury, 1991). Para Nierenberg (1973:2), a "negociação é um negócio que pode afetar intensamente qualquer tipo de relacionamento humano e produzir acrescimentos duradouros para todos os participadores”. Segundo Pruitt (1981), a negociação é definida como a comunicação entre as partes com interesses divergentes, a fim de chegar a um acordo.

A incerteza quanto às possibilidades de soluções, a emergência de um amplo leque de conflitos, de natureza e tipos dos mais variados que entremeiam os mais diversos interesses e 
papéis representados entre as partes, exigem dessas que a negociação seja tratada de forma processual, facilitando o acordo consensual.

Kersten e Noronha (1999) classificam esse caráter processual da negociação em três fases principais: a pré-negociação, a negociação e a pós-negociação. A etapa de pré-negociação envolve a compreensão do problema, suas questões e opções, os posicionamentos e os interesses entre a(s) parte(s) e os fatores externos que podem influenciar. É o momento de preparação para a negociação propriamente dita. A elaboração das pautas e agendamentos, definição dos objetivos da negociação são atividades que fazem parte dessa etapa. A fase de negociação propriamente dita é o momento em que as propostas e contrapropostas são colocadas na mesa para avaliação. É a própria condução da negociação, onde as partes agem segundo estratégias próprias. É nesse estágio que ocorre a negociação propriamente dita para o ajuste dos interesses conflitantes. E na pós-negociação ocorre a dinâmica dos processos de feedback avaliando os resultados obtidos e a elaboração do termo de compromisso. Nessa fase pode-se também avaliar o grau de satisfação das partes envolvidas.

Tão importante quanto cumprir as etapas do processo de negociação é compreender o estilo que a caracterizará e direcionará as ações do negociador durante as diversas fases até o momento da deliberação; este perfil do negociador também influenciará na qualidade da tomada de decisão.

Inerente à compreensão do estilo, sobressai a questão do comportamento do papel (Capranico, 1997). Os participantes de um processo de negociação representam diferentes papéis relacionados às suas atuações na própria situação de negociação, como aquelas originárias das instituições de que esses são provenientes.

Capranico (1997), ao discutir a teoria do papel, explica que implícita no conceito de papel desempenhado em uma situação de jogo como a de negociação se revela a dimensão da mediação. O papel é mediador ao envolver tanto os aspectos prescritivos e normativos como os elementos pessoais, originais e criativos ancorados pelo modo como o indivíduo interpreta e representa o seu papel. Nesse sentido, uma organização multiatores de negociação está baseada em um mosaico de papéis, sendo estes interpretados e construídos entre seus diversos participantes, relevando-se, portanto, a discussão sobre o exercício da aprendizagem da mediação do papel desempenhado (Capranico, 1997).

Desta forma, o saber desempenhar um papel e o saber se posicionar no decorrer do processo da mediação entre os papéis poderão fazer uma grande diferença uma vez que, participando da mesa de negociação, o desempenho dos diferentes papéis e o uso de estilos diferenciados possibilitarão que várias e diferentes situações possam ser apropriadamente apreendidas e trabalhadas.

O estilo de negociação pode ser definido como a descrição das características de comportamento de um indivíduo envolvido em um encontro de negociação, incluindo a impressão inicial, as atribuições de situações vivenciadas, as questões de outras fontes não relacionadas ao conhecimento e o comportamento subsequente durante as negociações (Gottschalk, 1974). 
Existem várias abordagens utilizadas para identificar o estilo de negociação que variam de acordo com as percepções dos autores. O jogo de interesses permite que emoções e comportamentos se apresentem na negociação. Van Lange (1992) mostrou que pessoas pró-sociais, por exemplo, esperam mais cooperação do que pessoas egoístas. Adotar posturas com tendências pró-sociais ou egoístas influencia no comportamento do negociador tornando a dinâmica da negociação cooperativa ou competitiva (Van Kleef e De Dreu, 2002). A percepção "perde-ganha" se relaciona então a uma postura competitiva em que os atores envolvidos usam de estratégias coercitivas para ganhar sempre mais nas negociações, e a percepção "ganha-ganha" correlaciona-se com a postura cooperativa, onde as partes buscam a complementaridade dos interesses. Essas percepções refletem-se também nas estratégias de negociação, caracterizando as posições duras, que têm por objetivo "aplicar alguma forma de coerção ao opositor", e aquelas suaves, que são orientadas para "negociar em forma de concessão" (Braga, 1998).

Para cada estilo encontram-se respectivamente práticas de negociação que lhe são características. Segundo Rahim (2002), o estilo caracterizado como de integração envolve as práticas da receptividade, da troca de informações, da procura de alternativas e do exame das diferenças visando à resolução dos problemas entre as partes. $\mathrm{O}$ estilo dominação se baseia em um posicionamento coercitivo orientado para o poder, ignorando as necessidades e expectativas das partes em jogo. O estilo acomodação está associado à tentativa de minimizar as diferenças, enfatizando pontos em comum, no intuito de satisfazer os interesses das outras partes. O estilo evasão está associado com o se esquivar, com o retrocesso e a desresponsabilização, sendo inapropriado ao tratar questões importantes e/ou complexas. E o estilo concessão mútua, no qual os atores abrem mão de parte dos interesses em jogo para chegarem a uma decisão aceitável por todos.

Independentemente dos papéis e estilo de negociação assumido, torna-se fundamental favorecer a criação de um contexto que facilite e promova a comunicação clara e eficiente, estimule a cooperação, proporcionando maior habilidade para tomar decisões e administrar os conflitos, potencializando assim a capacidade para superar os impasses emergentes (Martinelli e Almeida, 2009).

Bohm (2005:29) explica que a palavra comunicação se origina do latim commun, com o sufixo ie, que é semelhante a fie, que significa "fazer" ou "pôr em prática". Assim, um dos significados de "comunicar" é "fazer alguma coisa junto". Segundo Lempereur, Colson e Duzert (2009), comunicar-se metodicamente é um prerrequisito para a boa negociação e envolve a capacidade de saber escutar e falar de modo eficaz. Para os autores, em negociação as palavras fazem a diferença e a escuta justifica-se como meio de desenvolver um relacionamento com o outro; nesse sentido, existem muitas formas de aprender a escutar, a falar e, consequentemente, a negociar.

Para Quaglino, Casagrande e Castellano (1992), o ouvir não é uma dimensão banal da comunicação, definindo-a como um evento dialético entre diferenciação e uniformidade. A diferenciação relaciona-se à posse de informações, dados, conhecimentos, entendidos como a visão profissional ligada ao problema em discussão. A uniformidade deriva do reconhecimen- 
to da situação comum na qual se está operando e do valor atribuído à comunicação de cada membro para a solução do problema. Ainda segundo os autores, do ponto de vista relacional, o ouvir se apresenta como uma atividade correlata às vivências alternantes entre a suspeita e a confiança. A suspeita se determina do temor da perda do próprio ponto de vista e do consequente conflito que poderá ser derivado da presa de posicionamento. A confiança nasce do conhecimento dos próprios limites e da capacidade de perceber os outros como recursos úteis para superá-los (Quaglino, Casagrande e Castellano, 1992).

Por outro lado, o ouvir faz parte da competência da observação e do diálogo. Capranico (1997), ao evidenciar a aprendizagem por meio do exercício da representação de um papel em uma dada situação de jogo de interesses, põe em discussão a dimensão da observação. Para o autor, o setting do jogo estimula ações pouco formalizadas, improvisadas e em parte desconexas como impulsos criativos, motores e sensoriais. Para o autor, a leitura desses cenários advinda do ato de observar pode atingir diferentes níveis de profundidade, sendo esta dependente das competências cognitivas e afetivas do observador. Nesse sentido, a aprendizagem da observação, do imprevisto e ou do improvisado condicionam a direção do olhar de quem observa ao privilegiar ou não determinadas facetas da compreensão.

De forma análoga, para Bohm (2005), na dimensão do diálogo os significados emergentes são similares, mas não idênticos. Desse modo, os interlocutores percebem e consideram esta diferença como algo de novo, e assim o processo reflexivo vai e vem, com a emergência contínua de novos conteúdos que são comuns aos participantes do diálogo. Essa corrente de significados flui entre as pessoas perpassando e ampliando-se para a totalidade do grupo, emergindo daí novas compreensões. Esta reflexividade compartilhada é a "cola" ou "amálgama" que mantém juntas as pessoas em um determinado contexto (Bohm, 2005).

É na criação desse contexto coletivo de observação, de escuta, de reflexão e de comunicação, do pôr em prática e fazer alguma coisa junto que emerge o potencial criativo do diálogo, possibilitando que um conjunto de atores envolvido num processo de negociação desenvolva práticas de aprendizagem social que lhes estão subjacentes, tornando-o mais fluido e eficaz à obtenção do consenso e da resolução dos problemas colocados na mesa.

\section{A perspectiva da aprendizagem social: a participação na prática e a reflexividade}

As perspectivas de estudo da aprendizagem organizacional (AO) se distinguem, conforme Easterby-Smith e Araújo (2001), entre aprendizagem como um processo técnico e como um processo social. No processo técnico a aprendizagem é tida como processo cognitivo, de entrega, repasse de conhecimento de forma unidirecional. No processo social, que é fortemente debatido a partir dos anos 1990 e se configura como uma resposta crítica aos modelos tradicionais do cognitivismo, a aprendizagem é tida como um fenômeno que emerge das relações sociais por meio da interação em um contexto sociocultural (Gherardi, Nicolini e Odella, 1998; Gherardi, Nicolini e Strati, 2007).

O caráter social da aprendizagem, conforme Brown e Duguid (1991), indica onde ela está localizada, não estando mais, conforme o cognitivismo, na mente dos sujeitos e sim no 
ambiente onde ocorre a participação dos indivíduos em atividades sociais. Consequentemente, o conhecimento é gerado a partir das relações entre os atores e das interpretações desenvolvidas por estes, significando que o saber não é uma atividade separada do próprio curso da vida, nem é exclusivo de espaços restritos ou segregados por tipo de atividade (Gherardi, Nicolini e Odella, 1998).

Nessa perspectiva, a aprendizagem é socialmente construída, com foco na maneira como as pessoas atribuem significado às suas experiências, e está fortemente entrelaçada ao contexto onde está inserida, sendo, por isso, construída pela realidade e construtora dessa realidade. Esta abordagem social tem como preocupação central compreender a natureza das interações sociais que promovem o contexto propício para a aprendizagem, pois nessa perspectiva sociológica o conhecimento, os sujeitos e os objetos do conhecimento são produzidos em conjunto a partir de uma prática situada, mediados pelas relações sociais, estando a aprendizagem integrada ao cotidiano de vida dos atores envolvidos (Gherardi, Nicolini e Odella, 1998).

Nesse sentido, a prática pode ser definida, segundo Gherardi (2006:118), como uma "textura de conexões em ação", a conectividade que liga ações enquanto essas se multiplicam e se propagam. Para Schatzki (2006), a prática é um arranjo espaço-temporal de ações organizadas em constante evolução. Esses arranjos são constituídos de bens materiais e esquemas de trabalho, ideias, informação, estilos, linguagem, histórias e documentos que são partilhados pelos membros da comunidade. Muitas vezes o termo é equiparado à rotina ou a alguma atividade que as pessoas estão fazendo num dado contexto espaço-temporal. O conhecimento é algo que as pessoas fazem juntas e está intimamente ligada à prática situada num contexto; nesse sentido, a aprendizagem é sempre uma realização prática (Gherardi, 2006).

Releva-se ainda a ênfase colocada por Schatzki (2006) de que uma organização, como qualquer fenômeno social, é caracterizada como um conjunto de práticas enquanto arranjos de pessoas, materiais e artefatos. Para o autor, uma organização é constituída pelos sucessivos eventos que acontecem em um contexto espaço-temporal, sendo este acontecimento baseado no desempenho de suas ações constituintes.

Logo, a partir de Reckwitz (2002) e Schatzki (2006), pode-se atentar que as teorizações que enfocam as práticas são aquelas que observam as práticas como unidade social genérica primária, ou seja, são caracterizadas pela criação do social localizado nas práticas, sendo essa a menor unidade de análise social.

Gherardi e Nicolini (2001) desenvolvem estudos direcionados a AO embasados em dois conceitos empregados na sociologia: participação em práticas e reflexividade, sugerindo a substituição da ideia de aprendizagem organizacional pelo conceito de "learning-in-organizing" - "aprender-ao-organizar". Nessa concepção, aprender pode ser entendido como participação competente em uma prática, forma de transformação ou perpetuação de um conhecimento, produção e reprodução do social. Tal abordagem prática é considerada um conjunto de atividades no qual o saber não é desligado do fazer, enfatizando as situações em que elas coproduzem conhecimento por meio da atividade. Portanto, a prática torna-se um tópos que vincula saber e fazer (Gherardi, 2008). 
Nesse sentido, Nicolini, Gherardi e Yanow (2003) relevaram em seus estudos a abordagem relacionada aos fenômenos de knowing e organizing a partir de um aspecto baseado em prática. Esses trabalhos desenvolvidos por Gherardi $(2006,2008)$ vêm investigando a ideia de conhecimento proposta por Reckwitz (2002). Tal autor constrói a noção de tensão indo além das dicotomias, a partir de uma visão holística, tratando o knowing/conhecimento como uma dinâmica indissociável.

Na perspectiva proposta por Nicolini, Gherardi e Yanow (2003), o knowing antecede o conhecimento, tanto no aspecto lógico quanto cronológico, já que o conhecimento é considerado uma interpretação institucionalizada do knowing, e o knowing consiste em atividades e processos em constante evolução que se perpetuam no correr do tempo, formas de saber e fazer construídas coletivamente, relacionais e mediadas por artefatos (Gherardi, 2006).

\subsection{A prática de aprendizagem da negociação e da negociação da aprendizagem em organizações multiatores}

Conforme indicado, a abordagem das questões socioambientais nas organizações compostas por múltiplos atores baseia-se em papéis, estilos e estratégias de negociação que podem ser considerados fundamentais na análise das práticas de aprendizagem.

Para Muro e Jeffrey (2008), a prática da aprendizagem social nos contextos de múltiplos atores consiste em um fenômeno natural que ocorre sempre que partes interessadas se reúnem para lidar com suas diferenças, mas que, por outro lado, esse potencial exige o cultivo das oportunidades de aprendizagem para que estas contribuam para a gestão sustentável dos recursos naturais.

Nessa linha de discussão, alguns autores, ao iluminarem as diferentes perspectivas envolvidas no processo de negociação, têm articulado a abordagem da aprendizagem social como prática que contribui na obtenção de consensos e na tomada de decisões. Segundo esses autores, os referenciais da aprendizagem social se inserem nas práticas socioambientais educativas de caráter colaborativo, tendo se revelado como importante veículo na construção de uma nova cultura de diálogo e de participação (Jacobi, Granja e Franco, 2006; Glasser, 2007; Kilvington, 2007; Leys e Vanclay, 2010; D’Angelo e Brunstein, 2013).

De forma semelhante, Warner (2005), ao discutir as diferentes perspectivas envolvidas nos processos de negociação, enfatizou a dimensão da aprendizagem social ao afirmar que as pessoas mudam as coisas ao aprenderem juntas: "os processos multiatores se baseiam na negociação ou na aprendizagem social através do diálogo?” (Warner, 2005).

Seguindo estes questionamentos, se pressupôs nesta pesquisa que a participação no contexto de uma organização multiatores se releva como importante prática de aprendizagem da negociação e da negociação da aprendizagem que lhe é subjacente.

Por outro lado, evidencia-se, segundo Elkjaer (2001), que a simples participação em práticas coletivas de trabalho não favorece a aprendizagem, pois os indivíduos aprendem por meio da reflexão, reorganização e reconstrução de suas experiências. 
Objetivando contextualizar estes pressupostos, releva-se que Jacobi, Granja e Franco (2006:6), ao citarem Beck (1997), enfatizaram a questão da reflexividade na atual sociedade produtora de riscos, possibilitando estabelecer a complexa discussão das relações entre meio ambiente e educação em prol de uma sociedade sustentável: "Os riscos contemporâneos explicitam os limites e as consequências das práticas sociais, trazendo com eles um novo elemento: a 'reflexividade"'.

Além do diálogo reflexivo, Jacobi, Granja e Franco (2006) afirmam que a problemática socioambiental representa também a possibilidade de abertura de espaços para implementar alternativas diversificadas de democracia participativa, em especial o acesso à informação e a consolidação de canais abertos para uma participação plural. Esses espaços envolveriam um conjunto de atores em todos os níveis, potencializando o engajamento dos diversos sistemas de conhecimento, a capacitação de profissionais e a comunidade em geral numa perspectiva interdisciplinar e intersetorial (Jacobi, Granja e Franco, 2006).

Consoante com estas assertivas, releva-se a proposta de Keen, Brown e Dyball (2005), ao enfatizar que a aprendizagem social no contexto da questão socioambiental se refere, sobretudo, à gestão de mudanças. Para os autores, a aprendizagem social é considerada uma ação e reflexão que ocorre em fóruns coletivos, envolvendo a interação e o compartilhamento de conhecimentos entre diferentes grupos de indivíduos, em prol de melhor negociar a mudança social (Keen, Brown e Dyball, 2005).

Ao considerar o knowing fenômeno sociocultural, Gherardi (2006) afirmou que este possibilita a exploração de facetas do conhecimento consideradas de menor intencionalidade, menor instrumentalidade e maior reflexividade, representando, por fim, uma precondição para que ocorra a aprendizagem, tornando a própria prática, em um movimento de açãodiálogo-reflexão-ação, como ponto de partida para empreender mudanças (Gherardi, 2006; Ipiranga, Faria e Amorim, 2008).

Wenger e Snyder (2000) também discutiram a concepção da aprendizagem social como um fenômeno situado, indicando a interação como um componente crítico do aprendizado ao envolver os participantes em comunidade, mediante relacionamentos de engajamento mútuo e confiança que "atam" o grupo em uma entidade social.

Nessa linha de pensamento, Leys e Vanclay (2010) sugeriram que os mecanismos de socialização baseados no engajamento, na confiança e na empatia são catalisadores para a emergência de práticas de aprendizagem social no contexto das plataformas multiatores, visando a resolução das questões socioambientais.

Nesse contexto e conforme evidencia Easterby-Smith e Araújo (2001), grupos de pessoas de diferentes organizações e background culturais diversos que se encontram por um período de tempo, tendo como meta analisar um problema ou desenvolver um projeto, plasmam, por conseguinte, uma comunidade discursiva. Segundo os autores, esse processo gera uma identidade discursiva situada, possibilitando aos participantes comparar diferentes perspectivas e realizar o que permaneceu remanescente, não comunicado, isolado e, eventualmente, os discursos que conflitaram. Essa situação, ao se basear no posicionamento e no jogo dos papéis assumidos e interpretados, desencadeia a afirmação de identidades desenvolvendo 
uma competência para agir ao possibilitar o deslocamento entre as fronteiras de diferentes comunidades, promovendo a aprendizagem de como negociar relacionamentos atuais e de como negociar as mudanças nesses relacionamentos (Easterby-Smith e Araújo, 2001; Nicolini, Gherardi e Yanow, 2003).

Kilvington (2010) pondera que se torna importante, portanto, entender a aprendizagem social não como um modelo direcionado para como as coisas deveriam ser feitas, mas sim como um conjunto de premissas e situações cuja gestão influencia o desenvolvimento de práticas de aprendizagens dos multiatores organizados no sentido de encontrar seus próprios caminhos na resolução dos problemas socioambientais.

Nesse sentido, Jacobi, Granja e Franco (2006) relatam que, no decorrer da interação entre os múltiplos e diferentes atores que se reúnem em um fórum para discutirem problemáticas socioambientais, se destacam, entre outras, as estratégias da participação e da negociação que engloba as práticas do envolvimento e da corresponsabilidade, através das quais pode ser observada a prática de construção e reconstrução de decisões conjuntas, iluminando os processos cooperativos de obtenção de consensos gradativos, como facilitadores para a prática da resolução de conflitos.

Para os autores, esses processos criativos de ação interativa entre múltiplos atores podem ser considerados uma sucessão de negociações e renegociações, permanentes e contínuas, voltadas para a melhoria da tomada de decisão e para a seleção de alternativas na definição de um curso de ação, envolvendo: i) a análise da situação-problema, ii) as escolhas estratégicas, iii) os acordos com visões compartilhadas dos atores intervenientes (Jacobi, Granja e Franco, 2006).

Warner (2005) coaduna com esta perspectiva quando releva que, no contexto dos processos multiatores, a comunicação se transforma em um veículo para a troca de informação e construção de conhecimentos, facilitando a disseminação de ideias dentro e fora da organização. Nesse processo contínuo de mútua colaboração, os atores aprendem fazendo, adquirem novas informações e desenvolvem novas formas de pensar, devido à sua participação reflexiva e situada em um determinado contexto.

Portanto, se pressupõe que a participação reflexiva no contexto de uma organização multiatores se releva como importante prática de aprendizagem da negociação e da negociação da aprendizagem que lhe é subjacente, ao reunir no decorrer dos processos da negociação em si um conjunto de atividades no qual os saberes (knowing) relacionados aos papéis e estilos colocados em ato pelos multiatores estão vinculados aos conhecimentos e aos fazeres (organizing) construídos e reconstruídos coletivamente (Gherardi, 2006; Nicolini, Gherardi e Yanow, 2003; Reckwitz, 2002).

\section{Procedimentos metodológicos}

A estratégica metodológica utilizada para direcionar a pesquisa foi o estudo de caso qualitativo (Bauer e Gaskell, 2002). Como contexto de estudo, o Conselho Estadual do Meio Ambiente (Coema) do estado do Ceará foi escolhido por se caracterizar como uma organiza- 
ção multiatores, com atuação no espaço público, que se reúnem mensalmente para discutir e negociar uma agenda de questões concernente à área socioambiental (Mostert, 2003; Warner, 2005).

A coleta de dados foi feita mediante o uso de diferentes instrumentos, entre estes, a entrevista semiestruturada com perguntas abertas que tiveram como base para a sua formulação as dimensões teóricas e empíricas articuladas nos objetivos dessa pesquisa, quais sejam: i) a identificação dos atores participantes do Coema; ii) a composição do Coema como uma organização multiatores; iii) as relações entre os processos de negociação do Coema e as práticas de aprendizagem social que lhe são subjacentes. Foram realizadas seis entrevistas com os participantes do Coema, incluindo o presidente, a assessora e quatro conselheiros do Coema.

Considerando a natureza qualitativa dos procedimentos da pesquisa e, sobretudo, o objetivo de se descrever "práticas", relevam-se ainda os insights provenientes das anotações organizadas durante a aplicação do método da observação participante dos autores desse trabalho em 12 reuniões de negociações acontecidas no Coema durante o período de outubro de 2011 a fevereiro de 2013.

A observação participante foi exercida tendo como base a ideia segundo Bruyn (1966), que a define como um processo de interação entre teoria e métodos dirigidos pelo pesquisador em sua busca de conhecimento não só da perspectiva humana como do próprio contexto social. Nesse sentido, para compor os procedimentos observacionais buscou-se aplicar o conceito de Goffman (2011) sobre a interação face a face como uma classe de eventos que ocorre durante e por causa da copresença, sendo estes "pequenos comportamentos" constitutivos dos movimentos faciais como as olhadelas, dos gestos, dos papéis, posicionamentos e enunciados verbais que as pessoas continuamente inserem na situação de uma ocasião social organizada: "Eles são os sinais externos de orientação e envolvimento — estados mentais e corporais que não costumam ser examinados em relação à sua organização social" (Goffman, 2011:9).

Considerando os objetivos desta pesquisa, o formulário que orientou os procedimentos das observações participantes focalizou a descrição dos comportamentos, enunciados verbais e práticas que foram observadas pelos pesquisadores durante as reuniões do Coema, relacionadas: i) aos perfis, estilos e papéis assumidos pelos atores durante as três diferentes fases dos processos de negociação; ii) às práticas de negociação e às práticas de aprendizagem social subjacentes.

Tendo como base as anotações e os insights colhidos durante os procedimentos das observações participantes, foi ainda utilizada a técnica da entrevista como situação relacional (Spink, 1999). A entrevista como situação relacional teve como objetivo confirmar e validar as anotações e os insights elaborados durante a fase das observações participantes. Esta foi aplicada com diferentes atores participantes em diversas reuniões do Coema, totalizando uma média de 15 atores entrevistados. Este tipo de entrevista, segundo Spink (1999), é compreendido como fruto da interação entre sujeitos ativos, incluindo nessa interação o próprio pesquisador.

Foram ainda compilados e analisados documentos institucionais do Coema como atas de reunião, regimento interno, política estadual de meio ambiente, entre outros acessados no 
site do Conselho, possibilitando a triangulação de técnicas de coleta a favor do enriquecimento da interpretação (Spink, 1999).

Segundo Easterby-Smith e Araújo (2001) e Schatzki (2006), os pesquisadores, ao contemplarem as práticas de aprendizagem, focam as atividades, o que viabiliza que a linguagem seja vislumbrada como atividade discursiva e o Coema como uma comunidade discursiva. Este princípio teórico e epistemológico orientou a construção do plano de análise que teve como base a abordagem das práticas discursivas e a produção de sentidos no cotidiano segundo Spink (1999). Esta abordagem que se baseia nos pressupostos do construtivismo social problematiza o contexto discursivo, focalizando a análise no momento da interação, pois o lócus da aprendizagem não está na cabeça das pessoas, mas nas relações sociais, sendo algo que estas fazem juntas. Nesse sentido, as descrições e explicações sobre o mundo são artefatos e formas de ação social, estando entremeadas pelas atividades humanas (Gergen, 1985; Spink, 1999).

Tendo como base esses procedimentos e considerando a abordagem das práticas discursivas e produção de sentidos no cotidiano segundo Spink (1999), buscou-se identificar os repertórios interpretativos como unidade de construção das práticas discursivas. Os repertórios interpretativos incorporam os posicionamentos dos sujeitos em interação, estando estes inseridos num constante processo de negociação delineando este espaço de interpessoalidade (Spink, 1999).

A análise propriamente dita foi compreendida à luz de categorias e informações contextuais variadas originadas da imersão dos pesquisadores no campo empírico e dos dados relevados através dos instrumentos de coleta utilizados, fazendo emergir a interpretação como elemento intrínseco do processo de pesquisa. Não havendo, assim, momentos distintos entre o levantamento de informações e a interpretação. Dessa forma, começando com a definição das categorias temáticas que refletiram, sobretudo, os objetivos dessa pesquisa, este mapeamento levou ao delineamento das dimensões empírico-analíticas, possibilitando uma aproximação dos sentidos vistos como atividade-fim (Spink, 1999).

Tendo como base os pressupostos e objetivos desta pesquisa, os resultados e as discussões foram apresentados através de um "texto aberto" (Strati, 2007), no qual se articulam trechos selecionados do repertório interpretativo construído a partir das seguintes categorias empírico-analíticas: i) O Coema como uma organização multiator e; ii) as práticas de aprendizagem da negociação e da negociação da aprendizagem social subjacente.

\section{Contextualização, interpretação e discussões dos resultados}

\subsection{Coema como uma organização multiatores}

Conforme material analisado da compilação documental, se releva que o Coema é um órgão colegiado, vinculado diretamente ao governador do estado do Ceará, com jurisdição em todo 
o estado. Sua criação ocorreu nos termos da Lei no 11.411, de 28 de dezembro de 1987, integrando o Sistema do Meio Ambiente. O Conselho tem por finalidade assessorar o chefe do Poder Executivo em assuntos de política de proteção socioambiental.

A estrutura do Coema é composta, atualmente, por 35 participantes, sendo dois representantes da Assembleia Legislativa do Estado e um representante das demais entidades do poder público, das universidades, ambientalistas interessados, sociedade civil e representantes de classes profissionais de nível superior. Os participantes do Conselho têm um mandato com a duração de dois anos passível de prorrogação.

As reuniões do colegiado do Coema são realizadas ordinariamente uma vez ao mês, em datas fixadas em calendário estabelecido mediante deliberação e, extraordinariamente, toda vez que convocado pelo presidente ou a requerimento de $1 / 3$ de seus membros, com antecedência mínima de 48 horas.

As deliberações do colegiado são tomadas, em regra, por maioria simples de votos presentes à reunião, cabendo ao presidente o voto de conselheiro e de desempate, este último se em segunda discussão persistir o empate. As resoluções e moções são datadas e enumeradas em ordens distintas, cabendo à Secretaria Executiva ordená-las e indexá-las. Quando aprovadas, são referendadas e assinadas pelo presidente, cabendo à Secretaria Executiva dar o seu devido encaminhamento.

Tendo como base a metáfora da mesa-redonda de negociação, esta composição caracteriza o Coema como uma organização multiatores, pois aberta ao escrutínio público, na qual os participantes com seus diferentes papéis e perspectivas interagem, construindo em um espaço coletivo multi-interessados diálogos, visando à tomada de decisão e da ação concertada na abordagem das questões socioambientais (Jacobi, Granja e Franco, 2006; Mostert, 2003; Roling e Woodhill, 2001; Warner, 2005).

Conforme evidenciam Easterby-Smith e Araújo (2001) grupos de pessoas de diferentes organizações e background culturais diferentes, ao se encontrarem por um período de tempo, tendo como meta analisar um problema ou desenvolver um projeto, constroem identidades situadas constituindo, por conseguinte, uma comunidade discursiva. De forma análoga, Schatzki (2006) enfatizou que uma organização, como qualquer fenômeno social, é constituída pelos sucessivos eventos que acontecem em um contexto espaço-temporal, sendo este acontecimento baseado no desempenho de suas ações constituintes.

Nesse sentido, e ao considerar os objetivos dessa pesquisa, as práticas participativas emergentes das negociações multiatores do Coema podem ser aqui consideradas uma unidade social genérica primária que possibilitou a construção do social (Reckwitz, 2002; Schatzki, 2006). Esta inferência corrobora ainda com o princípio metodológico, segundo Spink (1999), de que os repertórios interpretativos incorporam os posicionamentos dos sujeitos em interação, estando estes inseridos num constante processo de negociação delineando um espaço de interpessoalidade, uma comunidade discursiva: no caso desse estudo, a evidência da organização multiatores do Coema (Easterby-Smith e Araújo, 2001). 


\subsection{As práticas de aprendizagem da negociação e da negociação da aprendizagem na organização multiatores do Coema}

Tendo como base os repertórios interpretativos construídos, diversos saberes, papéis e estilos de negociação colocados em ato pelos atores do Coema foram identificados. Durante as fases da pré-negociação das sessões observadas, e considerando a situação do conjunto de atores que participavam do fórum, relevaram-se "pequenos comportamentos" no jogo de papéis emergente da escuta e da interação face a face congruente com as descrições de diferentes estilos de negociação (Capranico, 1997; Goffman, 2001).

Alguns atores pareciam se distanciar das discussões abstendo-se de emitir suas opiniões, num ato participativo de observação e escuta e/ou, em alguns casos, no ato característico da evasão, subentendendo uma "obrigação em se fazer presente". Em negociação as palavras fazem a diferença e a escuta justifica-se como meio de desenvolver um relacionamento com o outro. Nesse sentido, infere-se que nesta fase inicial da negociação alguns comportamentos estavam relacionados às atividades alternantes da suspeita e da confiança no ato da escuta (Gottschalk, 1974; Kersten e Noronha, 1999; Lempereur, Colson e Duzert, 2009; Quaglino, Casagrande e Castellano, 1992).

Por outro lado, verifica-se que autores como Wenger e Snyder (2000) e Leys e Vanclay (2010) corroboram estas inferências ao enfatizarem a questão da interação como um componente crítico do aprendizado, envolvendo os participantes mediante relacionamentos de engajamento mútuo, empatia e confiança que "atam" o grupo em uma entidade social, facilitando a construção de práticas de aprendizagem social.

Outro comportamento evidenciado durante as observações de uma das sessões do processo multiatores do Coema foi o estilo dominador, que aconteceu quando um conselheiro impôs veementemente sua proposta por meio de práticas de argumentação orientada ao poder, posicionando-se coercitivamente em relação aos demais posicionamentos de discordância. Com a percepção por parte dos demais atores dessa postura competitiva de caráter "perde-ganha", infere-se das observações que estes ensaiaram posicionamentos conflitivos de acomodação e evasivos a partir das tentativas de alguns atores de abandonarem a mesa de negociação antes do término da sessão (Braga, 1998).

Essa evidência sugere que, embora os processos multiatores do Coema estejam organizados para um diálogo aberto, o caminhar da negociação também caracteriza práticas conflitivas de desacordo e desconfiança, processos esses que podem limitar as possíveis soluções dos problemas colocados na mesa e, dessa forma, devem ser abordados.

Esses estilos revelados durante as fases de pré-negociação — o da escuta, o evasivo, o da acomodação, do desacordo e da desconfiança — parecem ter estimulado, por outro lado, a prática entre alguns atores da formação de pequenos subgrupos, confrontando assim o perfil dominador com um posicionamento pró-social orientado à complementaridade de interesses (Braga, 1998; Van Kleef e De Dreu, 2002).

As práticas de negociação desencadeadas a partir da influência do estilo de um dos participantes caracterizado como dominador dificultaram a concessão mútua entre as demais 
partes que não abriram mão de seus interesses, seja através do estilo evasivo, da acomodação, do desacordo e da desconfiança, seja através da divisão da plenária com a formação de subgrupos. Este jogo de interesses conflitivo baseado em posições duras e competitivas do tipo "perde-ganha" estimulou o aflorar de comportamentos e emoções que dificultaram a obtenção do consenso e, consequentemente, a resolução dos problemas que estavam colocados na mesa de negociação (Braga, 1998; Rahim, 2002; Van Lange, 1992).

Evidencia-se ainda que este episódio observado se apoia também na discussão, segundo Capranico (1997), ao enfatizar o caráter mediador do papel desempenhado em uma situação de jogo de interesses conflitivos, envolvendo tanto os aspectos prescritivos e normativos como os elementos emocionais, imprevistos e criativos ancorados pelo modo como os negociadores o interpretam e o representam.

Nesse sentido e conforme Lempereur, Colson e Duzert (2009), independentemente dos papéis e estilos da negociação, é fundamental estabelecer práticas que promovam a comunicação eficiente no sentido de fazer ou pôr em prática alguma coisa junto a partir da ampliação do diálogo, da construção de novos significados, potencializando a capacidade para superar os impasses emergentes, tendo em vista o ajuste dos interesses conflitantes (Bohm, 2005; Martinelli e Almeida, 2009).

Observou-se que durante estes momentos da pré-negociação o presidente da mesa manteve um posicionamento de observação e escuta dos processos em curso, promovendo a partir da emergência das posições conflitantes, e através de um estilo integrativo, as práticas da troca de informações, da procura de alternativas e do exame das diferenças para chegar a uma solução aceitável pelas partes. Conforme entrevista realizada com o presidente do Coema:

(...) se os conselheiros evadirem da votação, aí eu não estou sabendo conduzir meu colegiado, eu não estou sabendo presidir o colegiado porque não estou conseguindo levar ele a cumprir seu papel que é de negociar, obter consenso e deliberar (...).

(...) meu o papel como presidente e o do secretário executivo é criar um ambiente favorável para que ocorra a deliberação e (...) feito esta parte, as demais etapas de negociação até a deliberação ocorrem no próprio plenário com as manifestações pró e contra, recomendações até que se delibere. Esse é um processo nosso de tomada de decisão. (Presidente do Coema)

A análise de repertórios das entrevistas e das observações revelou que o contexto de negociação do Coema, além de ser um fórum multiatores caracterizado por um mosaico de papéis e, portanto, pela participação plural ao acolher uma ampla diversidade de pontos de vistas, é distinguido também como um fórum de caráter técnico. Dessa forma, as deliberações são baseadas na diferenciação e uniformidade do ato do ouvir e na colaboração mediante o diálogo, facilitando que esses conhecimentos técnicos e profissionais sejam compartilhados de forma criativa entre os participantes:

(...) é preciso ficar claro que esse é um processo de negociação, mas antes de tudo é um processo de deliberação de natureza técnica e dessa forma, salvo exceções, as reuniões são mais colaborativas do que competitivas. (Presidente do Coema) 
(...) quando o conflito surge a gente tenta mediar os interesses divergentes para produzir uma solução de consenso, então é uma dinâmica interessante porque é no diálogo e debate do plenário que, às vezes, se formula recomendação de mudança de relatório, recomendação de ajustes, pedem-se esclarecimentos adicionais ao empreendedor e ao técnico (...). (A2)

Conforme afirmado pelo presidente e pelo conselheiro (A2), é possível inferir que a interação conflitiva emergente entre as partes se caracterizou como o ponto de partida para o desencadear de práticas da aprendizagem da negociação, ao mobilizar novos conhecimentos e saberes (knowing) sobre as questões socioambientais postas à mesa para discussão. Observouse a partir daí que se deu início às práticas da escuta confiante, dos processos reflexivos do diálogo, do vaivém de posicionamentos que eram comuns e uniformes a alguns participantes, unindo os fios de significados, uma "textura de conexões em ação" que fluiu entre os demais, conectando e ligando práticas que se multiplicaram e se propagaram, possibilitando novas compreensões (Gherardi, 2006).

(...) Houve um amadurecimento no entender que o ato de negociar é isso, você não consegue impor o seu pensamento à maioria, você tem que ceder e ganhar alguns pontos e ceder em outros e isso também foi extremamente positivo na minha atividade profissional e no aprendizado como pessoa. (A2)

Além disso, os elementos práticos da escuta, do diálogo e da reflexividade que se relevam dessas análises estão consoantes com as discussões de Gherardi (2006), ao considerar que o knowing possibilita a exploração de facetas do conhecimento consideradas de menor intencionalidade, menor instrumentalidade e maior reflexividade, representando, por fim, uma precondição para que ocorra a aprendizagem, tornando a própria prática como ponto de partida para empreender mudanças (Bohm, 2005; Gherardi, 2006; Quaglino, Casagrande e Castellano, 1992).

Releva-se ainda que o posicionamento do presidente da mesa facilitou a criação de um contexto de comunicação propício à obtenção do consenso, caracterizando a fase da negociação propriamente dita na qual as partes demonstraram estar receptivas à escuta e ao diálogo, agindo segundo suas próprias estratégias (organizing), desencadeando os processos de feedbacks ao envolver a avaliação das propostas e das contrapropostas, como enfatizado nos trechos a seguir (Kersten e Noronha, 1999).

(...) Eu achei incompleta a apresentação. Eu queria saber qual a fase que vai gerar empregos? (...). Eu queria saber se tem algum programa de formação, mesmo sendo uma usina automática, qual a capacitação dos técnicos em nossa área, em nosso Estado? (...). Gostaria de saber se haverá um estudo sobre a sustentabilidade do empreendimento já que envolverá uma área muito grande, até mesmo porque a região está muito sensível à questão de manter as espécies nativas e os demais recursos naturais. Estas questões não ficaram claras. (Ata da 211aㅡ Reunião Ordinária do Coema, p. 3) 
Observou-se que estas práticas de negociação — da escuta e do diálogo, do agir segundo suas próprias estratégias (organizing), dos feedbacks, das avaliações das propostas e das contrapropostas - possibilitaram uma maior reflexividade das participações, incidindo na ampliação da participação com a entrada na arena de atores que até então se posicionavam em silêncio na periferia da mesa da negociação, entre estes, atores externos ao Coema, conforme os trechos seguintes articulados:

(...) dependendo do projeto em discussão no Coema como esse da construção da usina, ocorre uma maior discussão, inclusive com atores externos ao Coema, e, em consequência, um aprendizado maior sobre determinadas questões socioambientais (...). (Assessora do Coema).

Dessa forma, os momentos deliberativos da pós-negociação se caracterizaram pela conciliação dos interesses, por meio da circularidade da troca coletiva de informações, do espelhamento e exame das diferenças e pela busca de alternativas para a solução de impasses emersos, facilitando a negociação com a construção da decisão conjunta e a resolução dos problemas colocados na mesa (Kersten e Noronha, 1999; Rahim, 2002).

Infere-se que a reflexividade e a ampliação da prática da participação entre os atores foram facilitadas pela construção e reconstrução das experiências, constituindo identidades coletivas, possibilitando que o conhecimento (knowing) subjacente aos problemas colocados na mesa fosse socializado e coletivamente construído (organizing) (Brown e Duguid, 1991; Gherardi, Nicolini e Odella, 1998; Elkjaer, 2001), nas palavras dos entrevistados:

(...) é lógico que nesse processo de discussão, de deliberação, há uma construção de conhecimento, há um processo de aprendizagem indiscutivelmente. Claro que a aprendizagem e a apropriação do conhecimento vão variar de ator pra ator, de participante pra participante, de tema para tema, de momento a momento, até porque as temáticas que aparecem são eminentemente técnicas e aparecem de forma caótica, ou seja, há um processo de construção do saber organizado, sistemático, em uma sessão nós vamos entender o que é isso, na próxima reunião nós vamos trabalhar tal conteúdo, que leva a uma construção planejada ou dirigida por todos. Então, o processo de negociação é caótico e nós o organizamos, hoje eu estou discutindo energia eólica, amanhã eu estou discutindo mineração, semana que vem estou discutindo outros assuntos. Se produz um aprendizado em termos do processo de negociação em si e de deliberação. (A2)

(...) Com certeza houve um grande aprendizado durante as minhas participações nas reuniões do Coema, eu mesmo na minha atividade comecei a conduzir os projetos imobiliários que a gente administra com mais atenção na questão dos bens intangíveis agregando valor à comercialização dos empreendimentos imobiliários que, por exemplo, não estão obrigados por lei a ter coleta seletiva de lixo, mas terminam tendo por deliberação dos empreendedores. Ao final da aquisição do imóvel, aquele que optar por usar energia solar no aquecimento da água terá $10 \%$ de redução na taxa condominial. Nenhuma dessas estratégias a gente teria agregada ao nosso negócio, à 
nossa vida, se não fosse o aprendizado que a gente obteve através das participações do Coema. Houve sim uma mudança de comportamento. (A4)

Esses elementos que "aparecem de forma caótica" no jogo de interesses observados e enfatizados na entrevista de A2, além de iluminarem o caráter mediador dos papéis, se relacionam com os posicionamentos pouco formalizados, improvisados e em parte desconexos, os impulsos criativos, motores e sensoriais que caracterizam as práticas de aprendizagem (knowing) colocadas em ato pelos participantes e subjacentes ao processo de negociação propriamente dito. Esta leitura interpretativa se reporta à aprendizagem do imprevisto decorrente das práticas da observação e da escuta, privilegiando determinadas facetas de compreensão (knowing) das questões que estavam sendo colocadas na mesa de negociação (Gherardi, 2006; Capranico, 1997).

Por outro lado, esse jogo entre variados papéis, este espelhamento e comparação entre diferentes perspectivas, o compartilhamento de diversas facetas do conhecimento (knowing) promoveram a aprendizagem de como negociar em um movimento de observação-ação-diálogo-reflexão, desenvolvendo, por fim, uma competência para agir (organizing) no trabalho e na vida, como relevado pelos entrevistados A2 e A4 (Elkjaer, 2001; Gherardi, 2006; Kilvington, 2007; Ipiranga, Faria e Amorim, 2008; Leys e Vanclay, 2010).

Conforme trechos documentais abaixo descritos recortados da $210^{\mathrm{a}}$ Ata e da entrevista do presidente do Coema, infere-se que este processo reflexivo possibilitou a aprendizagem da mediação e da colaboração com a "construção do saber organizado" (organizing), subjacentes a este conjunto de práticas e eventos que aconteceram de forma sucessiva (knowing), criando novos espaços interativos, viabilizando o engajamento mútuo, plasmando, por conseguinte, uma comunidade discursiva em prol da mudança comportamental e social (Keen, Brown e Dyball, 2005).

(...) até agora pelo entendimento das discussões é possível a gente organizar os processos: o Comitê de Emergência vai solicitar construir um conjunto de barragens subterrâneas (...). Então, eu acho perfeitamente possível o que o conselheiro da Aeac propôs, de o Comitê informar a natureza da intervenção aos municípios onde essas são consideradas emergenciais e aí a parte da documentação que será solicitada vai se determinar se se enquadra no documento " $\mathrm{X}$ " do Comitê e assim por diante. (...). Politicamente esse processo tem que ser tratado dessa forma. (Ata da 210ª Reunião Ordinária, p. 8)

(...) nós estamos tentando reorganizar no sentido de tornar a organização dos processos cada vez mais transparentes para todos os conselheiros e participantes, então a ideia de acesso fácil à informação, a ideia do diálogo direto entre todos, não só com os conselheiros, mas também com as instituições e organizações que eles representam e são aqui representadas. (Presidente do Coema)

Nesse processo de mútua colaboração criativa, os atores, ao atribuírem significado às suas experiências, aprenderam fazendo, adquiriram novas informações, desenvolveram novas 
formas de pensar e agir com novos posicionamentos no decorrer das sucessivas e contínuas interações, se destacando diversas e diferentes práticas de aprendizagem da negociação e da negociação da aprendizagem social que lhes são subjacentes, entre estas:

As práticas de aprendizagem da negociação e da negociação da aprendizagem social evidenciadas na fase da pré-negociação: Interação face a face; Distanciamento das discussões; Posicionamentos de observação e escuta; Evasão; Acomodação; Desconfiança; Desacordos; Atividades alternantes de suspeita e da confiança; Interesses conflitivos; Abandono da mesa; Jogos de papéis; Prática de formação de subgrupos; Perfil dominador versus posicionamento pró-social;

As práticas de aprendizagem da negociação e da negociação da aprendizagem social evidenciadas na fase da negociação propriamente dita: Mobilização de novos conhecimentos e saberes (knowing); Papéis assumidos pelo presidente da mesa; Promoção de práticas para a troca de informações; Estilo integrativo; Mediação dos papéis, Práticas de comunicação; Ampliação da escuta e do diálogo; Negociação de novos significados (knowing); Avaliação de propostas e contrapropostas; Complementaridade de interesses; Ampliação da participação; Participação reflexiva; Agindo a partir de suas próprias estratégias (organizing).

As práticas de aprendizagem da negociação e da negociação da aprendizagem social evidenciadas na fase da pós-negociação: Circularidade e troca coletiva de informações (knowing); Espelhamento e exames das diferenças; Busca de alternativas; Reflexividade; Resolução dos pontos conflitantes; Práticas cooperativas de obtenção de consensos gradativos; Práticas de construção de decisão conjunta; Construção do saber organizado e deliberações (organizing); Desenvolvimento da competência para agir.

As práticas evidenciadas de aprendizagem da negociação favoreceram a negociação da aprendizagem social, possibilitando a melhoria da tomada de decisões e das escolhas estratégicas na abordagem das questões socioambientais tratadas no Coema. Por outro lado, essa participação reflexiva e competente em uma prática, como forma de transformação ou perpetuação de um conhecimento e do "aprender-ao-organizar", influenciou, por fim, o próprio acontecer da organização multiatores do Coema (Gherardi e Nicolini, 2001; Jacobi, Granja e Franco, 2006; Schatzki, 2006).

\section{Considerações finais}

Conforme a análise da comunidade discursiva constituída pelos participantes do Coema, as práticas subjacentes aos papéis, estilos e diálogos colocados em ato emergiram da mesa de negociação como unidades sociais primárias que possibilitaram o aflorar do social localizado nas práticas de aprendizagem a estas relacionadas. Estas atividades participativas, ao serem executadas de forma situada, estimularam novas práticas no decorrer das etapas de negociação que por meio de uma trama de conexões em ação se multiplicaram e se propagaram continuamente, ampliando esse espaço discursivo e resultando, por fim, na caracterização da organização multiatores do Coema. 
Evidenciou-se que, apesar de em parte esse aprender ter sido propiciado por uma plataforma multiatores estruturada por um órgão público, qual seja, o Coema do Governo do Estado do Ceará, foi colocado em ato e em uso pelos diversos e múltiplos participantes a partir da construção de um contexto organizacional complexo e, sobretudo, por meio das lógicas que lá prevaleciam.

Nesses termos, o percurso de análise aqui apresentado procurou articular uma compreensão das atividades participativas e dos processos do saber e do fazer (learning-in-organizing) que lhes foram correspondentes como um espaço não unívoco de práticas. Relevando-se ainda o caráter reflexivo que delineou papéis, posicionamentos e negociações que demarcaram as ações constituintes dos sujeitos em um contexto espaço-temporal, perpassando a esfera normativa dos processos de deliberação, sendo nestes interstícios e fronteiras que os processos da organização multiatores do Coema aconteceram.

A lógica subjacente a esses processos não estava relacionada a um conhecimento como um corpo autônomo de proposições, mas permeada de novas identidades e modos de ação constituída em curso, que delinearam novas imagens do mundo e diferentes perspectivas negociais que atuaram nos processos deliberativos, promovendo oportunidades de aprendizagem da negociação e da negociação da aprendizagem no contexto da organização multiatores sob estudo.

Foi do entrelaçamento destas práticas — desse jogo entre knowing e competências que emergiu o sujeito negociador de seus papéis e posicionamentos, articulando uma apropriação subjetiva em face da objetivação do discurso de atuação na abordagem das questões socioambientais colocadas à mesa de negociação do Coema.

Diante da análise realizada, observa-se que as práticas de negociação reveladas no decorrer de suas três diferentes fases estão intimamente ligadas à participação reflexiva e às diferentes práticas da aprendizagem da negociação acontecidas na organização multiatores sob estudo, entre estas: as práticas da observação, da escuta, da interação face a face e em subgrupos, as práticas do espelhamento, do exame das diferenças e do envolvimento, do diálogo, da mediação, da circularidade e do compartilhamento de informações, a prática do feedback e da resolução dos pontos conflitantes e dos processos cooperativos de obtenção de consensos gradativos e, por fim, a prática de construção de decisão conjunta e deliberativa. Por ser o Coema uma instituição que objetiva assessorar o Estado nas políticas e abordagens das questões socioambientais, o conhecimento (knowing) articulado pelos multiatores envolvidos emerge tangenciando sua organização propriamente dita.

Por outro lado, esse mosaico de papéis colocados em ato pelos multiatores participantes do Coema desencadeou o potencial criativo da escuta e do diálogo ao negociarem experiências e informações que esses trouxeram para a mesa, assim como ao transladarem esses conhecimentos construídos para as organizações e instituições que esses representavam. Esse processo reflexivo do aprender a mediar constituído no vaivém de significados influenciou a ampliação do social, possibilitando a translação de informações relevantes em área de diferentes saberes e indo além do espaço organizacional do Coema. 
Nesse sentido, evidencia-se que os repertórios interpretativos articulados nesta pesquisa, ao realçarem as práticas em constante evolução (knowing), baseada na vinculação entre o aprender e o organizar, entre o saber e o fazer (learning-in-organizing), propiciando aprendizagem enquanto participação reflexiva em uma comunidade discursiva, iluminaram uma contribuição teórica importante para ser desenvolvida em estudos futuros, relacionada à questão da circularidade e transformação do conhecimento nos processos de organizar que são transladados entre os múltiplos atores de uma organização complexa.

Essas articulações teóricas empíricas evidenciaram a relevância da presente pesquisa, ao indicar uma lacuna na literatura ainda não suficientemente explorada pertinente à compreensão das ações conjuntas que se negociam, circulam, se transformam e se reproduzem em uma organização multiatores, como práticas de aprendizagem da negociação e da negociação da aprendizagem social.

Releva-se, ainda, a importância desse estudo no sentido de fornecer subsídios relacionados aos processos de negociação em espaços públicos e à construção de pactos de governança no contexto da abordagem das questões socioambientais. Estas discussões, ao terem por base a perspectiva da aprendizagem social e, portanto, contribuindo para a recente discussão sobre a aprendizagem para a sustentabilidade, poderão subsidiar a formulação de políticas e apoiar a gestão pública dos cada vez mais escassos recursos naturais e socioambientais.

Como limitação do trabalho releva-se o fato de esse estar circunscrito a um estudo de caso de um setor público específico. Nesses termos, algumas questões para estudos futuros, inclusive em outros contextos multiatores — públicos e/ou privados — podem ser colocadas, entre estas: como ocorrem a circulação e a transformação de conhecimentos nos processos do aprender e do organizar em diversas organizações que participam de uma plataforma multiatores?

\section{Referências}

BAUER, Martin W.; GASKELL, George. Pesquisa qualitativa com texto, imagem e som. Um manual prático. Petrópolis: Vozes, 2002.

BECK, Ulrich. A reinvenção da política. In: GIDDENS, Anthony; BECK, Ulrich; LASH, Scott. Modernização reflexiva: política, tradição e estética na ordem social moderna. São Paulo: Unesp, 1997. p. 11-71.

BOHM, David. Diálogo: comunicação e redes de convivência. São Paulo: Palas Athenas, 2005.

BOUWEN, René; TAILLIEU, Tharsi. Multi-party collaboration as social learning for intederpendence: developing relational knowing for sustainable natural resource management. Journal of Community \& Applied Social Psychology, v. 14, n. 3, p. 137-153, maio/jun. 2004.

BRAGA, Douglas G. Conflitos, eficiência e democracia na gestão pública. Rio de Janeiro: Fiocruz, 1998. 
BROWN, John S.; DUGUID, Paul. Organizational learning and communities of practice: towards a unified view of working, learning, and innovation. Organization Science, v. 2, n. 1, p. 40-58, fev. 1991.

BRUYN, Severyn T. The human perspective in sociology. The methodology of participant observation. Nova Jersey: Prentice-Hall, Inc. Inglewood Cliffs, 1966.

CAPRANICO, Sergio. Role playing. Manuale a uso di formatori e insegnanti. Milão: Raffaello Cortina, 1997.

D'ANGELO, Márcia J.; BRUNSTEIN, Janette. Aprendizagem social para a sustentabilidade: Um estudo sobre negócios sustentáveis em contextos de múltiplos atores sociais, relações e interesses. In: ENCONTRO DA ASSOCIAÇÃO NACIONAL DE PESQUISA E PÓS-GRADUAÇÃO EM ADMINISTRAÇÃO, XXXVII, 2013, Rio de Janeiro.

DORE, John; LEBEL, Louis. Gaining public acceptance: a critical strategic priority of the World Commission on Dams. Water Alternatives, v. 3, n. 2, p. 124-141, 2010. Disponível em: <www.wateralternatives.org >. Acesso em: 9 out. 2012.

EASTERBY-SMITH, Mark; ARAÚJO, Luís. Aprendizagem organizacional: oportunidades e debates atuais. In: EASTERBY-SMITH, Mark; BURGOYNE, John; ARAÚJO, Luís. Aprendizagem organizacional e organização de aprendizagem. Desenvolvimento na teoria e na prática. São Paulo: Atlas, 2001. p. 16-38.

ELKJAER, Bente. Em busca de uma teoria social de aprendizagem. In: EASTERBY-SMITH, Mark; BURGOYNE, John; ARAÚJO, Luís (Org.). Aprendizagem organizacional e organização de aprendizagem. Desenvolvimento na teoria e na prática. São Paulo: Atlas, 2001. p. 100-118.

ELKJAER, Bente; WAHLGREN, Bjarne. Organizational learning and workplace learning — similarities and differences. In: ANTONACOPOULOU, Elena et al. (Org.). Learning, working and living. Mapping the terrain of working, life, learning. Nova York: Palgrave Macmillan, 2005. p. 15-29.

FERREIRA, Aracéli C. S. Contabilidade ambiental: uma informação para o desenvolvimento sustentável. São Paulo: Atlas, 2003.

FISHER, Roger; URY, William L. Getting to yes: negotiating agreement without giving in. Boston: Hougton Mifflin Company, 1991.

GERGEN, Kenneth J. The social constructionist movement in modern psychology. American Psychologist, v. 40, n. 3, p. 266-275, mar. 1985.

GHERARDI, Silvia. Organizational knowledge: the texture of workplace learning. Oxford: Blackwell, 2006.

GHERARDI, Silvia. Situated knowledge and situated action: what do practice-based studies promise? In: BARRY, Daved; HANSEN, Hans. New approaches in management and organization. Londres: Sage, 2008. p. 516-527.

GHERARDI, Silvia; NICOLINI, Davide. The sociological foundations of organizational learning. In: DIERKES, Meinolf et al. (Org). Handbook of organizational learning and knowledge. Londres: Oxford University Press, 2001. p. 35-60. 
GHERARDI, Silvia; NICOLINI, Davide; ODELLA, Francesca. Toward a social understanding of how people learning in organizations: the notion of situated curriculum. Management Learning, v. 29, n. 3, p. 273-297, set. 1998.

GHERARDI, Silvia; NICOLINI, Davide; STRATI, Antonio. The passion for knowing. Organizations, v. 14, n. 3, p. 315-330, maio 2007.

GLASSER, Harold. Minding the gap: the role of social learning in linking our stated desire for a more sustainable world to our everyday actions and policies. In: WALS, Arjen E. J. Social learning: towards a sustainable world. Netherlands: Wageningen Academic Publishers, 2007. p. 35-61.

GOFFMAN, Erving. Ritual de interação. Ensaios sobre o comportamento face a face. Petrópolis: Vozes, 2011.

GOTTSCHALK, Andrew W. G. Cedep teaching notes. 1974. Mimeografado.

HARMONICOP. Social learning pool of questions. An instrument to diagnose social learning and IC-tools in European river basin management. HarmoniCOP combined WP2/WP3 deliverable. K.U.Leuven - Centre for Organizational and Personnel Psychology, 2003.

HEMMATI, Minu. Multi-stakeholder processes for governance and sustainability. Before deadlock and conflict. Londres: Earthscan, 2002.

IPIRANGA, A. S. R.; FARIA, Vilma C. M.; AMORIM, Mônica A. A comunidade de prática da rede NÓS: colaborando e compartilhando conhecimentos em arranjos produtivos Locais. Organização \& Sociedade, v. 15, n. 44, p. 149-170, jan./mar. 2008.

JACOBI, Pedro R.; BARBI, Fabiana. Democracia e participação na gestão dos recursos hídricos no Brasil. Revista Katálysis, v. 10, n. 2, p. 237-244, jul./dez. 2007.

JACOBI, Pedro R.; GRANJA, Sandra I. B.; FRANCO, Maria I. Aprendizagem social: práticas educativas e participação da sociedade civil como estratégias de aprimoramento para a gestão compartilhada em bacias hidrográficas. São Paulo em Perspectiva, v. 20, n. 2, p. 5-18, abr./jun. 2006.

KEEN, Meg; BROWN, Valeria A.; DYBALL, Rob (Ed.). Social learning in environmental management: towards a sustainable future. Londres: Easthscan, 2005.

KERSTEN, Gregory E.; NORONHA, Sunil J. WWW — based negotiation support: design, implementation and use. Decision Support Systems, v. 25, n. 2, p. 135-154, mar. 1999.

KILVINGTON, Margareth. Buiding capacity for social learning in environmental management. Tese. (doutorado em filosofia) — Lincoln University, Canterbury, Nova Zelândia, 2010.

KILVINGTON, Margareth. Social learning as framework for building capacity to work on complex environment management problems. Landcare Research, Nova Zelândia, 2007. Disponível em: <http://landcareresearch.co.nz/publications/researchpubs>. Acesso em: 31 ago. 2013.

LEYS, Andrea J.; VANCLAY, Jerome K. Stakeholder engagement in social learning to resolve controversies over land-use change to plantation forestry. Regional Environmental Change, v. 11, n. 1, p. 175-190, jun. 2010. 
MARTINELLI, Dante P.; ALMEIDA, Ana P. de. Negociação e solução de conflitos: do impasse ao ganha-ganha através do melhor estilo. São Paulo: Atlas, 2009.

MOSTERT, Erik. Public participation and the European water framework directive: a framework for analysis, 2003. Disponível em: <http://harmonicop.info/_files/_down/HarmoniCOPinception. pdf $>$. Acesso em: 14 abr. 2012.

MURO, Melanie; JEFFREY, Paul. A critical review of the theory and application of social learning in participatory natural resource management processes. Journal of Environment Planning and Management, v. 51, n. 3, p. 325-344, maio 2008.

NICOLINI, Davide; GHERARDI, Silvia; YANOW, Dvora (Ed.). Knowing in organizations: a practicebased approach. Armonk: M. E. Sharpe, 2003.

NIERENBERG, Gerard I. Fundamentals of negotiating. Nova York: Harper \& Row, 1973.

OLIVEIRA, Filipi A.; SINISGALLI, Paulo A. A. Plataformas multiatores e aprendizagem social: uma gestão ambiental efetiva na APA municipal Embu Verde. In: ENCONTRO NACIONAL DA ASSOCIAÇÃO DE PESQUISA E PÓS-GRADUAÇÃO EM AMBIENTE E SOCIEDADE, V, 2010, Florianópolis. Disponível em: <www.anppas.org.br/encontro5/cd/artigos/GT12-166-416-20100903200250. pdf>. Acesso em: 20 ago. 2013.

PAHL-WOSTL, Claudia. Towards sustainable in the water sector - the importance of human actors and processes of social learning. Aquatic Sciences, v. 64, n. 4, p. 394-411, dez. 2002.

PRUITT, Dean G. Negotiation behaviour. Nova York: Academic Press, 1981.

QUAGLINO, Gian P.; CASAGRANDE, Sandra; CASTELLANO, Anna M. Gruppo di lavoro. Lavoro di gruppo. Um modello di lettura della dinamica di gruppo. Una proposta di intervento nelle organizzazioni. Milão: Rafaello Cortina, 1992.

RAHIM, M. Afzalur. Toward a theory of managing organizational conflict. The International Journal of Conflict Management, v. 13, n. 3, p. 206-235, 2002.

RECKWITZ, Andreas. Toward a theory of social practices: a development in culturalist theorizing. European Journal of Social Theory, v. 2, n. 5, p. 243-263, maio 2002.

ROLING, Niels; WOODHILL, Jim. From paradigms to practice: foundations, principles and elements for dialogue on water, food and environment. Background Document for the Workshop on National and Basin Dialogue Development Workshop, Bonn, December 1-2, 2001.

SCHATZKY, Theodore R. On organizations as they happen. Organization Studies, v. 27, n. 12, p. 1863-1873, dez. 2006.

SOUZA, Felipe A. Z.; BEDUSCHI FILHO, Luiz C. Aprendizagem social em plataformas multiatores: um olhar para os Conselhos Gestores de Unidades de Conservação. In: ENCONTRO NACIONAL DA ASSOCIAÇÃO DE PESQUISA E PÓS-GRADUAÇÃO EM AMBIENTE E SOCIEDADE, V, 2010, Florianópolis. Disponível em: <www.anppas.org.br/encontro5/cd/artigos/GT12-166-416-20100903200250.pdf > . Acesso em: 20 ago. 2013. 
SPINK, Mary J. (Org.). Práticas discursivas e produção de sentidos no cotidiano: aproximações teóricas e metodológicas. São Paulo: Cortez, 1999.

STEINS, Nathalie A.; EDWARDS, Victoria M. Platforms for collective action in multiple-use CPRs. In: "CROSSING BOUNDARIES", THE SEVENTH ANNUAL CONFERENCE OF THE INTERNATIONAL ASSOCIATION FOR THE STUDY OF COMMON PROPERTY, June 10-14, 1998, Vancouver, British Columbia, Canada. Disponível em: <www.indiana.edu/ iascp/abstracts/612.html> . Acesso em: 14 set. 2012.

STRATI, Antonio. Organização e estética. Rio de Janeiro: Editora FGV, 2007.

SWARTLING, Åsa G. et al. Social learning and sustainability: exploring critical issues in relation to environmental change and governance; SEI Project Report, Mistra-SWECIA Working Paper no 5. SEI, jan. 2011. Disponível em: <www.stockholmresilience.org/21/publications/artiklar/1127-2011-social-learning-and-sustainability-exploring-critical-issues-in-relation-to-environmentalchange-and-governance.html>. Acesso em: 20 ago. 2013.

TIPPET, Joanne et al. Social learning in public participation in river basin management: early findings from HarmoniCOP European case studies. Environmental Science and Policy, v. 8, n. 3, p. 287-299, jun. 2005.

VAN KLEEF, Gerben A.; DE DREU, Carsten K. W. Social value and impression formation: A test of two competing hypotheses about information search in negotiation. International Journal of Conflict Management, v. 13, n. 1, p. 59-77, 2002.

VAN LANGE, Paul A. M. Confidence in expectations: a test of the triangle hypothesis. European Journal of Personality, v. 6, n. 5, p. 371-379, fev. 1992.

WARNER, Jeroen. More sustainable participation? Multi-stakeholder platforms for integrated resource management. International Journal for Water Resources Development, v. 22, n. 1, p. 15-35, ago. 2006.

WARNER, Jeroen. Multi-stakeholder platforms: integrating society in water resource management? Ambiente \& Sociedade, v. 8, n. 2, p. 4-28, jul./dez. 2005.

WENGER, Etienne C.; SNYDER, William M. Communities of practice: the organizational frontier. Harvard Business Review, v. 78, n. 1, p. 139-145, jan. 2000.

Ana Sílvia Rocha Ipiranga é doutora em psicologia do trabalho e da organização pela Università degli Studi di Bologna (Itália) e professora adjunta do Programa de Mestrado Acadêmico em Administração da Universidade Estadual do Ceará (Uece). E-mail: ana.silvia@pq.cnpq.br.

Michelle Firmino Celestino Moreira é mestra em administração pela Universidade Estadual do Ceará (Uece). E-mail: firminomichelle@gmail.com.

Luma Louise Sousa Lopes é especialista em estratégia e gestão empresarial e aluna do Mestrado Acadêmico em Administração da Universidade Estadual do Ceará (Uece). E-mail: lumalouise@gmail.com. 
Luís André Aragão Frota é especialista em gestão de organizações sociais pela Universidade Estadual Vale do Acaraú (UVA) e aluno do Mestrado Acadêmico em Administração da Universidade Estadual do Ceará (Uece). E-mail: luisandrearagao@yahoo.com.br.

Luciana Madeira Barros Coimbra é mestra em administração pela Universidade Estadual do Ceará (Uece) e professora da Faculdade Sete de Setembro (FA7). E-mail: lucianabarros22@yahoo.com.br. 